\section{Patients want us to ask about their sexuality and gender}

\author{
Aidan Baron ${ }^{1,2}$
}

People with diverse gender identities (GI) and sexual orientations (SO) are our patients, but they are also our friends, employers and work-colleagues. Every day we work alongside people whose lives we share a part in, through our love for emergency medicine. We hear about their family lives, upcoming vacations and friends from out of town. Our colleagues are not defined by their relationships or families. Yet these aspects of their lives are important. They shape the patterns of daily living, priorities and values. It is by sharing these aspects of our lives that we build personal relationships with others; trust.

Patients with diverse genders and sexualities are not rare. They are seen and treated, often unknowingly by us every single day. And just like our colleagues and coworkers, their personal lives, while not defining who they are, influence how they live.

But patients with diverse GI/SO are different. And they are acutely aware of this. There continues to be well-documented ED and healthcare avoidance, particularly by patients with diverse GI, because of perceptions that their identities and physical gender expression would negatively impact the care they receive. $^{1}$

It is incumbent on us to make the ED, and every healthcare interaction, a space of trust.

Most patients want us to ask them about these things (with caveats). They desire a relationship with us; seeking trust, mutual respect and empathy. ${ }^{2}$ Disclosing GI and SO can be a nervewracking moment for a patient. A rapid calculation of risk versus benefit occurs, where patients look for clues in our speech, body language, demeanour and environment; to gauge whether their disclosure is likely to be received poorly, or with understanding. This causes

\footnotetext{
${ }^{1}$ Emergency, Cardiovascular, and Critical Care Research Group, Centre for Health and Social Care Research, Kingston University and St George's, University of London, London, UK

${ }^{2}$ Discipline of Paramedicine, School of Biomedical Sciences, Charles Sturt University, Bathurst, New South Wales, Australia
}

Correspondence to Aidan Baron; aidan1baron@gmail.com varying degrees of anxiety in almost every single healthcare encounter for people with GI/SO diversity. ${ }^{3}$

In this edition of EMJ, Kodakek ${ }^{4}$ and her team from the EQUALITY (Emergency Department Query for Patient Centered Approaches to Sexual Orientation and Gender Identity) mixed methods multiphase study ${ }^{5}$ in the USA examined the vast discrepancy between patient and healthcare professional attitudes towards routinely collecting information about GI and SO. Their qualitative investigation revealed a majority affirmation by patients that these questions should be asked. Interestingly, there was disagreement and reticence on the part of healthcare professionals regarding collecting this information. Many felt that this information was not clinically relevant as it was unlikely to impact on the care that GI/SO diverse patients received. Healthcare professionals claimed that patients are all treated equally, and therefore discrimination does not occur. However, a lack of discrimination does not equal the presence of empathy and understanding. By treating everyone 'the same' the prima facie assumption of heterosexuality as a default is perpetuated, further marginalising GI/SO diverse people.

Two excerpts from patient interviews in Kodakek's paper from this issue of EMJ perfectly articulate how we in healthcare have perhaps improperly approached this paradigm:

You are supposed to have this psychosocially supportive relationship [between providers and patients]. How can you do that if you don't know who this person is and where they are coming from?

You cannot treat everybody the same, everybody is different, okay? That's like having more than one child. You can't treat each child the same, you have to treat them according to who they are.

Most patients enrolled in the EQUALITY study felt that their GI/ SO was always relevant information for healthcare professionals, and that routinely asking all patients about their GI/SO removed the burden from these patients in having to single themselves out as different, while simultaneously reducing stigmatic attitudes.
There are however crucial caveats which impacted patient comfort and willingness to disclose GI/SO information. A lack of physical privacy (curtains are not soundproof contrary to common practice), the presence of family members in the room, a mistrust of how information is stored and clear non-verbal cues from providers which betray discomfort and awkwardness were all associated with negative patient perception and decreased willingness to disclose this information. ${ }^{6}$

Translating this research into practice can cause discomfort among healthcare professionals. We may be unfamiliar with the language or tools required to elicit the information desired without appearing uncomfortable and disjointed in an otherwise smooth patient interview. Phrases such as 'How would you like to be addressed?' and 'Do you have a partner? What is their Gender?' while by no means definitive, might provide a starting point for professionals still developing fluency in this new standard for history taking.

In summary, we should ask, they want to tell.

Contributors $A B$ has authored this editorial.

Competing interests None declared.

Provenance and peer review Commissioned; internally peer reviewed.

(c) Author(s) (or their employer(s)) 2019. No commercial re-use. See rights and permissions. Published by BMJ.

(D) Check for updates

To cite Baron A. Emerg Med J 2019;36:134-135.

Received 30 November 2018

Accepted 8 December 2018

Published Online First 10 January 2019

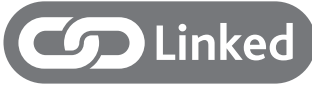

- http://dx.doi.org/10.1136/emermed-2018-207669

Emerg Med J 2019;36:134-135.

doi:10.1136/emermed-2018-208240

\section{REFERENCES}

1 Bauer GR, Scheim Al, Deutsch MB, et al. Reported emergency department avoidance, use, and experiences of transgender persons in Ontario, Canada: results from a respondent-driven sampling survey. Ann Emerg Med 2014;63:713-20. Internet.

2 Maragh-Bass AC, Torain M, Adler R, et al. Is It Okay To Ask: Transgender Patient Perspectives on Sexual Orientation and Gender Identity Collection in Healthcare. Acad Emerg Med 2017;24:655-67. Internet.

3 Chisolm-Straker M, Jardine L, Bennouna C, et al. Transgender and Gender Nonconforming in Emergency Departments: A Qualitative Report of Patient Experiences. Transgend Health 2017;2:8-16. 
4 Kodadek LM, Peterson S, Shields RY, et al. Collecting sexual orientation and gender identity information in the emergency department : the divide between patient and provider perspectives. Emerg Med J 2019;36:136-141.
5 Haider AH, Schneider EB, Kodadek LM, et al. Emergency Department Query for Patient-Centered Approaches to Sexual Orientation and Gender Identity: The EQUALITY Study. JAMA Intern Med 2017;177:819-28.
6 German D, Kodadek L, Shields R, et al. Implementing Sexual Orientation and Gender Identity Data Collection in Emergency Departments: Patient and Staff Perspectives. LGBT Health 2016:3:416-23. 